Sharif University of Technology
Scientia Iranica
Transactions E: Industrial Engineering
hCIENTIA

\title{
Project safety evaluation by a new soft computing approach-based last aggregation hesitant fuzzy complex proportional assessment in construction industry
}

\author{
H. Gitinavard ${ }^{\mathrm{a}}$, S.M. Mousavi ${ }^{\mathrm{b}}$, B. Vahdani ${ }^{\mathrm{c}}$, and A. Siadat , $^{\mathrm{d} *}$ \\ a. Young Researchers and Elite Club, South Tehran Branch, Islamic Azad University, Tehran, Iran. \\ b. Department of Industrial Engineering, Faculty of Engineering, Shahed University, Tehran, Iran. \\ c. Department of Industrial Engineering, Qazvin Branch, Islamic Azad University, Qazvin, Iran. \\ d. Laboratoire de Conception, Fabrication Commande, Arts et Métiers Paris Tech, Centre de Metz, Metz, France. \\ Received 20 December 2015; received in revised form 25 November 2016; accepted 20 May 2017
}

\author{
KEYWORDS \\ Safety evaluation; \\ Construction projects; \\ Soft computing; \\ Group decision \\ making; \\ Complex decision \\ analysis; \\ Hesitant Fuzzy Sets \\ (HFSs).
}

\begin{abstract}
In recent years, the implementation of safety management has increased in construction projects by institutions, and many companies have recognized environmental and social effects of damage to project work systems. In this regard, a novel decision model is presented based on a new version of complex proportional assessment method with last aggregation under a hesitant fuzzy environment. The Decision-Makers (DMs) assign their opinions by hesitant linguistic variables that are converted into the hesitant fuzzy elements. Also, the DMs' judgments are aggregated in the last step of decision-making process to decrease any information loss. Since the weights of the DMs or professional safety experts and evaluation criteria are not equal in practice, a new version of hesitant fuzzy compromise solution method is proposed to compute these weights. In addition, the criteria weights are determined based on the proposed hesitant fuzzy entropy method. A real case study in developing countries on the safety of construction projects is considered to indicate the suitability and applicability of the proposed new hesitant fuzzy decision model with the last aggregation approach. Besides, an illustrative example is prepared to show that the proposed approach is suitable and reliable for larger size safety problems.

(C) 2020 Sharif University of Technology. All rights reserved.
\end{abstract}

\section{Introduction}

In recent years, safety management has attracted considerable attention such that many organizations have tried to apply it as their main objective in order to prevent injuries, accidents, and other adverse results. In fact, it has been implemented by different companies in various industries whose processes and structures are related to the safety of operations. In addition,

\footnotetext{
*. Corresponding author. Tel.: +33 785122844 E-mail addresses: sm.mousavi@shahed.ac.ir (S.M. Mousavi); ali.siadat@ensam.eu (A. Siadat)
}

safety management has been applied to a number of industry sectors such as civil aviation [1-3], maritime industry $[4,5]$, railway industry $[6,7]$, manufacturing industry [8-10], and construction projects [11-15].

To cope with the issue, selecting the potential alternatives (e.g., construction-project work systems) versus conflicting safety evaluation criteria is a difficult decision problem, in which the Multi-Criteria DecisionMaking (MCDM) methods, such as Preferences Selection Index (PSI), Analytic Hierarchy Process (AHP), and Technique of Order Preference by Similarity to Ideal Solution (TOPSIS), could be applied to properly evaluate safety problems, considering the risk issues. In this respect, Schinas [16] surveyed the utilization and application of the MCDM methods in the safety 
assessment, and showed that only a few studies have considered the MCDM methods for safety problems in this area. Fazil et al. [17] presented a multi-criteria decision-analysis approach to selecting the food safety intervention among the balancing different criteria. Jozi and Pouriyeh [18] utilized the AHP method for evaluating risks in the combined cycle power plant of Yazd, Iran. Mangalathu et al. [19] used the AHP method to manage the safety of operations related to LPG-based gas furnace.

In many complex MCDM problems, DecisionMakers (DMs) or professional safety experts' opinions are not defined by crisp values in the safety management. Thus, most of the evaluations of potential safety alternatives or candidates could be regarded as imprecise/uncertain conditions. The fuzzy sets theory, first formalized by Zadeh [20], is a powerful tool that can help the DMs or managers with the safety management to overcome the uncertain conditions. Therefore, utilizing the classical fuzzy sets theory and their extensions could be attractive tools for researchers to solve the safety problems under imprecise situations in practice. Moreover, considering the fuzzy information in the procedure of developing a decision-making method could appropriately deal with the available imprecise information in the real cases. Recently, Kahraman et al. [21] investigated the latest status of fuzzy MCDM methods and categorized these fuzzy methods into fuzzy multi-attribute decision-making and fuzzy multi-objective decisionmaking approaches. In addition, they surveyed the most utilized fuzzy MCDM techniques by analyzing the publishing frequencies with respect to years, the most cited papers, and journals publishing them.

Regarding the literature of safety problems, Bao [22] proposed a hierarchical TOPSIS method under a fuzzy environment to combine individual safety performance indicators for a set of European countries into an overall index. Mojtahedi et al. [23] simultaneously considered project risk identification and assessment by applying multi-attribute group decisionmaking technique based on the health, safety, and environment factors in gas refinery plant construction. Mousavi et al. [24] focused on an approach to handling risks of large engineering projects by considering the concept of safety based on non-parametric resampling with interval analysis. Khorasani et al. [25] utilized the Simple Additive Weight (SAW) method for the assessment of road safety performances of 21 European countries based on 11 safety indicators. Then, they compared the results of SAW method by applying the AHP and fuzzy TOPSIS methods to show a suitable method for ranking the countries. Skorupski [26] proposed an approach based on MCDM in a fuzzy environment to solve the air traffic safety problem. In addition, in this study, the objective and subjective criteria are considered in the procedure of the proposed approach.

The survey of the literature indicates that the previous studies have not sufficiently considered the MCDM or fuzzy MCDM methods for solving the safety problems in their fields from the safety point of view. Further, the classical fuzzy sets theory used for defining complex problems and developing the group decision-making methods simultaneously in the field of safety decision problems has received poor attention. In this study, a new group decision model with the last aggregation is introduced based on hesitant fuzzy complex proportional assessment and compromise solution methods for safety evaluation in construction projects. For this purpose, a new version of the complex proportional assessment method is presented based on the Hesitant Fuzzy Sets (HFSs). Recently, the HFSs theory has been introduced by Torra and Narukawa [27] and Torra [28] first, which could assist DMs or professional safety experts in expressing their judgments by some membership degrees for a safety alternative under a set.

The HFS theory is known as a powerful tool in the literature that is applicable to hesitant situations and conditions. In this regard, Farhadinia [29] and $\mathrm{Yu}$ et al. [30] expressed that the HFSs can be considered in practical situations and real applications of MCDM problems due to a set of possible values for the membership; in addition, this extension of fuzzy sets theory ensures anonymity and privacy, and it prevents the psychic contagion of DMs. For instance, if two project safety experts express the same value, then the value will emerge only once, and this assessment can be described by Hesitant Fuzzy Elements (HFEs) [30]. Wang et al. [31] mentioned that the HFSs are helpful in handling the MCDM problems and expressing judgments under imprecise situations where DMs hesitate between several values before assigning their preferences. Zhang et al. [32] explained that the HFSs prepared an effective approach to decisionmaking problems when some membership values are possible for an object or criterion. Rodríguez et al. [33] provided an overview on theory of HFSs with the aim of preparing an obvious perspective on different tools, trends, and concepts regarding this extension of fuzzy sets theory. In this regard, numerous operations, such as union and intersection, were developed for HFSs; Pei and Yi [34] surveyed the properties and algebraic structures of these operations.

However, due to the presence of powerful logic and sets, some authors utilized the HFSs to solve their decision problems under uncertainty. In this respect, Yan [35] used the multi-attribute decision making by hesitant fuzzy information to solve the risk of marketing problem. Yu et al. [36] proposed generalized hesitant fuzzy Bonferroni mean and discussed 
the desirability of its properties in detail to solve the financial strategy planning in a Chinese enterprise. $\mathrm{Xu}$ and Zhang [37] focused on the deviation method for computing the criteria weights with incomplete information and presented a TOPSIS method for solving the energy policy selection problem. Liu and Rodríguez [38] proposed a fuzzy representation for comparative linguistic expressions based on hesitant fuzzy linguistic term sets, and this approach was applied to a TOPSIS model for solving the supplier selection problem. Liu [39] extended some aggregation operators for aggregating the hesitant fuzzy linguistic information, and then used them to develop some approaches to solving the electrical power system safety problem. Therefore, the HFSs could be regarded as a suitable tool for dealing with the available imprecise information in project safety decision-making problems due to their practicality and concentration on the related literature as a powerful tool to address the uncertainties in complex decision-making problems.

In addition, the interval-valued HFS, which was first introduced by Chen et al. [40] in terms of the HFSs, could assist the DMs by considering some intervalvalues membership degrees for an element under a set to decrease errors. Accordingly, some authors have considered the interval-valued HFSs theory to solve the complex decision-making problems. In this case, Chen et al. [40] extended a group decisionmaking approach regarding the interval-valued hesitant preference operations. Xu and Zhang [37] constructed an optimization model to compute the attributes' weights based on the maximizing deviation method. Then, they developed the TOPSIS technique based on interval-valued hesitant fuzzy situations to solve the decision-making problems. Farhadinia [41] developed two clustering algorithms by focusing on relationship between entropy, distance, and similarity measures for the interval-valued HFSs and HFSs. Li and Peng [42] presented some Hamacher operations regarding interval-valued HFSs, and then developed a practical approach to the evaluation of the shale gas areas. Zhang and Xu [43] proposed an intervalvalued-based programming model for group decisionmaking problems under hesitant fuzzy situations with incomplete preference over potential alternatives.

The survey of the literature shows scarce and limited sources concerning the introduction and determination of new criteria weights under uncertain conditions. For instance, Torra and Narukawa [44] discussed the weight selection methods regarding weighted mean and ordered weighted averaging operators. Fan et al. [45] presented an optimization model to specify the weights of each criterion regarding experts' fuzzy opinions and objective fuzzy decision matrixes. Wang and Parkan [46] prepared a general MCDM framework according to the subjective preferences and objective information to obtain weights of criteria under fuzzy conditions. Chen and Lee [47] developed a fuzzy AHP technique based on triangular fuzzy numbers for computing the attributes' weights of professional conference organizer. $\mathrm{Xu}$ and Zhang [37] extended an optimization model, according to the maximizing deviation method, in order to obtain the weight of each criterion under both hesitant fuzzy and intervalvalued hesitant fuzzy environments. In their study, a hybridized group decision-making technique was presented based on some steps to determine the weight of each criterion, and it was easy to use in comparison with the optimization model. Feng et al. [48] applied the TOPSIS method to solve the hesitant fuzzy MCDM problems, in which the weight of each attribute was completely known. Zhang et al. [32] prepared an objective weighting approach regarding Shannon information entropy based on hesitant fuzzy information.

This paper tailors an extended weighting method based on entropy method and HFSs to determine the weights of each safety evaluation criterion. However, some significant contributions that are considered in this study are expressed in sum as follows: (1) introducing a novel decision model in a hesitant fuzzy environment to decrease errors by a group of DMs or professional safety experts with the last aggregation; the proposed model can express preferences and judgments of experts by some membership degrees for an object (i.e., evaluating project work system) versus the safety criteria; (2) presenting a new version of the complex proportional assessment method to rank potential safety alternatives with the last aggregation in order to decrease the loss of data; (3) proposing an extended hesitant fuzzy entropy method to determine weights of safety criteria; (4) presenting a new version of hesitant fuzzy compromise solution method for specifying the weights of each DM or professional safety expert. Moreover, the proposed hesitant fuzzy group decision model is applied to evaluate the construction project system problem in a real case study from the safety point of view in developing countries; moreover, an illustrative example is prepared to demonstrate the suitability and reliability of the presented approach to larger size safety problems.

The structure of this paper is organized as follows. The basic concepts and operations in the HFSs are illustrated in Section 2. Then, the proposed decision model in HFS is presented in Section 3. In Section 4, a case study about the safety of the construction projects in developing countries is considered to demonstrate the verification and feasibility of the proposed approach. In addition, an illustrative example is provided to show the implementation of the proposed approach in large size safety problems. Finally, in Section 5, some conclusions and future studies are provided to end the paper. 


\section{Preliminaries}

In this section, some basic operations and concepts of HFSs are expressed to facilitate the proposed approach. In addition, the concepts of interval-valued HFSs and operations are defined to represent the counterparts of the proposed approach versus HFSs theory.

Definition 1 [49-51]. $X$ is defined as a reference set, and then the Intuitionistic Fuzzy Set (IFS) $E$ on $X$ is represented as $E=\left\langle x_{i}, \mu_{E}\left(x_{i}\right), \nu_{E}\left(x_{i}\right)\right\rangle$ for $x_{i} \in$ $X$. In addition, the membership and non-membership degrees are shown by $\mu_{E}\left(x_{i}\right)$ and $\nu_{E}\left(x_{i}\right)$, respectively. Accordingly, the following relation should be satisfied:

$$
0 \leq \mu_{E}\left(x_{i}\right)+\nu_{E}\left(x_{i}\right) \leq 1 \text { for } x_{i} \in X .
$$

Definition $2[\mathbf{2 7 , 2 8}] . \quad X$ is defined as a universe of discourse, and then a HFS as $E$ on $X$ is defined by function $h_{E}(x)$ where $X$ returns to subset of $[0$, 1]. Xia and Xu [52] showed the HFS by the following mathematical symbol:

$$
E=\left\{<x, h_{E}(x)>\mid x \in X\right\},
$$

where $h_{E}(x)$ is defined as the set of membership degrees for an element under subset of $[0,1]$, indicating the membership degree of element $x \in X$ to $E$.

Definition 3 [40]. $X$ is defined as a reference set, and then the interval-valued HFS on $X$ is represented as follows:

$$
\tilde{E}=\left\{\left\langle x_{i}, \tilde{h}_{\tilde{E}}\left(x_{i}\right)\right\rangle \mid x_{i} \in X, i=1,2, \ldots, n\right\},
$$

where $\tilde{h}_{\tilde{E}}\left(x_{i}\right)$ is the interval membership degree for an object $x_{i} \in X$ under set $E$. Indeed, $\tilde{h}_{\tilde{E}}\left(x_{i}\right)$ is defined as an interval-valued HFE that satisfies the following relation:

$$
\tilde{h}_{\tilde{E}}\left(x_{i}\right)=\left\{\tilde{\gamma} \mid \tilde{\gamma} \in \tilde{h}_{\tilde{E}}\left(x_{i}\right)\right\},
$$

where the interval number is $\tilde{\gamma}=\left[\tilde{\gamma}^{L}, \tilde{\gamma}^{U}\right]$, in which $\tilde{\gamma}^{L}$ and $\tilde{\gamma}^{U}$ are expressed as the lower and upper bounds of $\tilde{\gamma}$, respectively.

Definition 4. Some basic operations on HFSs are defined by considering the relationship between the HFE and IFS as follows [52]:

$$
\begin{aligned}
& \tilde{h}_{1} \oplus \tilde{h}_{2}=\cup_{\gamma_{1} \in \tilde{h}_{1}, \gamma_{2} \in \tilde{h}_{2}}\left\{\gamma_{1}+\gamma_{2}-\gamma_{1} \cdot \gamma_{2}\right\}, \\
& \tilde{h}_{1} \otimes \tilde{h}_{2}=\cup_{\gamma_{1} \in \tilde{h}_{1}, \gamma_{2} \in \tilde{h}_{2}}\left\{\gamma_{1} \cdot \gamma_{2}\right\}, \\
& h^{\lambda}=\cup_{\gamma \in h}\left\{\gamma^{\lambda}\right\}, \\
& \lambda h=\cup_{\gamma \in h}\left\{1-(1-\gamma)^{\lambda}\right\},
\end{aligned}
$$

where $\tilde{h}_{1}$ and $\tilde{h}_{2}$ are two HFSs, and also $\gamma_{1}$ and $\gamma_{2}$ are two HFEs. Moreover, Eqs. (5) and (6) represent the union and intersection, respectively. Eq. (7) is considered for the HFE exponentiation to a constant number $(\lambda)$. Also, Eq. (8) represents the multiplication of a constant number by a HFE.

Definition 5. $\tilde{h}, \tilde{h}_{1}$, and $\tilde{h_{2}}$ are assumed as three interval-valued HFEs, and then the basic relations are defined as follows [40]:

$$
\begin{gathered}
\tilde{h}^{\lambda}=\left\{\left[\left(\tilde{\gamma}^{L}\right)^{\lambda},\left(\tilde{\gamma}^{U}\right)^{\lambda}\right] \mid \tilde{\gamma} \in \tilde{h}\right\}, \lambda>0, \\
\lambda \tilde{h}=\left\{\left[1-\left(1-\tilde{\gamma}^{L}\right)^{\lambda}, 1-\left(1-\tilde{\gamma}^{U}\right)^{\lambda}\right] \mid \tilde{\gamma} \in \tilde{h}\right\} \\
\lambda>0, \\
\tilde{h}_{1} \oplus \tilde{h}_{2}=\left\{\left[\gamma_{1}^{L}+\gamma_{2}^{L}-\gamma_{1}^{L} \gamma_{2}^{L}, \gamma_{1}^{U}+\gamma_{2}^{U}-\gamma_{1}^{U} \gamma_{2}^{U}\right] \mid \tilde{\gamma}_{1}\right. \\
\left.\qquad \tilde{h}_{1}, \tilde{\gamma}_{2} \in \tilde{h}_{2}\right\}, \\
\tilde{h}_{1} \otimes \tilde{h}_{2}=\left\{\left[\gamma_{1}^{L} \gamma_{2}^{L}, \gamma_{1}^{U} \gamma_{2}^{U}\right] \mid \tilde{\gamma}_{1} \in \tilde{h}_{1}, \tilde{\gamma}_{2} \in \tilde{h}_{2}\right\}
\end{gathered}
$$

Definition 6. The generalizations of summation and multiplication operators in Eqs. (5) and (6) are defined, respectively, as follows [53]:

$$
\begin{aligned}
& \bigoplus_{i=1}^{n} h_{i}=\cup_{\gamma_{1} \in h_{1}, \gamma_{2} \in h_{2}, \ldots, \gamma_{n} \in h_{n}}\left\{1-\prod_{i=1}^{n}\left(1-\gamma_{i}\right)\right\}, \\
& \bigotimes_{i=1}^{n} h_{i}=\cup_{\gamma_{1} \in h_{1}, \gamma_{2} \in h_{2}, \ldots, \gamma_{n} \in h_{n}}\left\{\prod_{i=1}^{n} \gamma_{i}\right\} .
\end{aligned}
$$

Definition 7. $E=\left\{h_{1}, h_{2}, \ldots, h_{n}\right\}$ is considered as a collection of interval-valued HFEs, and then Eqs. (11) and (12) are developed as follows [54]:

$$
\begin{aligned}
\bigoplus_{i=1}^{n} h_{i}= & \cup_{\gamma_{1} \in h_{1}, \gamma_{2} \in h_{2}, \ldots, \gamma_{n} \in h_{n}} \\
& \left\{\left[1-\prod_{i=1}^{n}\left(1-\gamma_{i}^{L}\right), 1-\prod_{i=1}^{n}\left(1-\gamma_{i}^{U}\right)\right]\right\}, \\
h_{1} \otimes h_{2} \otimes \ldots \otimes h_{n}=\cup_{\gamma_{1} \in h_{1}, \gamma_{2} \in h_{2}, \ldots, \gamma_{n} \in h_{n}} & \otimes \\
& \left\{\left[\prod_{i=1}^{n} \gamma_{i}^{L}, \prod_{i=1}^{n} \gamma_{i}^{U}\right]\right\} .
\end{aligned}
$$

Definition 8. $h_{j}(j=1,2, \ldots, n)$ is considered as some of HFEs. Then, the Hesitant Fuzzy Geometric (HFG) and Hesitant Fuzzy Weighted Geometric (HFWG) relations are defined, respectively, as follows [52]: 


$$
\begin{aligned}
& H F G\left(h_{1}, h_{2}, \ldots, h_{n}\right)=\stackrel{\bigotimes}{j=1}_{j}^{n}\left(h_{j}\right)^{\frac{1}{n}} \\
&=\cup_{\gamma_{1} \in h_{1}, \gamma_{2} \in h_{2}, \ldots, \gamma_{n} \in h_{n}}\left\{\prod_{j=1}^{n}\left(\gamma_{j}\right)^{\frac{1}{n}}\right\},
\end{aligned}
$$

$$
\begin{aligned}
& H F W G\left(h_{1}, h_{2}, \ldots, h_{n}\right)=\bigotimes_{j=1}^{n}\left(h_{j}\right)^{w_{j}} \\
&=\cup_{\gamma_{1} \in h_{1}, \gamma_{2} \in h_{2}, \ldots, \gamma_{n} \in h_{n}}\left\{\prod_{j=1}^{n}\left(\gamma_{j}\right)^{w_{j}}\right\},
\end{aligned}
$$

where the weight vector of $h_{j}(j=1,2, \ldots, n)$ is defined by $w=\left(w_{1}, w_{2}, \ldots, w_{n}\right)^{T}$.

Definition 9. The Interval-Valued Hesitant Fuzzy Geometric (IVHFG) relation is defined as follows [40]:

$$
\begin{aligned}
\operatorname{IVHFG} & \left(\tilde{h}_{1}, \tilde{h}_{2}, \ldots, \tilde{h}_{n}\right)=\left(\bigoplus_{j=1}^{n}\left(\tilde{h}_{j}\right)^{\frac{1}{n}}\right) \\
= & \cup_{\tilde{\gamma}_{1} \in \tilde{h}_{1}, \tilde{\gamma}_{2} \in \tilde{h}_{2}, \ldots, \tilde{\gamma}_{n} \in \tilde{h}_{n}} \\
& \left\{\left[\prod_{j=1}^{n}\left(\gamma_{j}^{L}\right)^{\frac{1}{n}}, \prod_{j=1}^{n}\left(\gamma_{j}^{U}\right)^{\frac{1}{n}}\right]\right\} .
\end{aligned}
$$

Definition 10. The Interval-Valued Hesitant Fuzzy Weighted Geometric (IVHFWG) relation is defined as follows [55]:

$$
\begin{gathered}
I V H F W G\left(\tilde{h}_{1}, \tilde{h}_{2}, \ldots, \tilde{h}_{n}\right)=\left(\bigoplus_{j=1}^{n}\left(\tilde{h}_{j}\right)^{w_{j}}\right) \\
=\cup_{\tilde{\gamma}_{1} \in \tilde{h}_{1}, \tilde{\gamma}_{2} \in \tilde{h}_{2}, \ldots, \tilde{\gamma}_{n} \in \tilde{h}_{n}} \\
\left\{\left[\prod_{j=1}^{n}\left(\gamma_{j}^{L}\right)^{w_{j}}, \prod_{j=1}^{n}\left(\gamma_{j}^{U}\right)^{w_{j}}\right]\right\},
\end{gathered}
$$

where $w=\left(w_{1}, w_{2}, \ldots, w_{n}\right)^{T}$ are the weight vectors of $\tilde{h}_{j}(j=1,2, \ldots, n)$ and $w_{j}>0, \sum_{j=1}^{n} w_{j}=1$.

Definition 11. $h_{M}$ and $h_{N}$ are considered as two HFEs; then, Hamming and Euclidean distance measures for the HFEs are represented, respectively, as follows [56]:

$$
d\left(h_{M}, h_{N}\right)=\frac{1}{l_{x_{i}}} \sum_{j=1}^{l_{x_{i}}}\left|h_{M}^{\sigma(j)}-h_{N}^{\sigma(j)}\right| .
$$

Also, the distance measure between them is as follows:

$$
d\left(h_{M}, h_{N}\right)=\sqrt{\frac{1}{l_{x_{i}}} \sum_{j=1}^{n}\left|h_{M}^{\sigma(j)}\left(x_{i}\right)-h_{N}^{\sigma(j)}\left(x_{i}\right)\right|^{2}},
$$

where the $j$ th largest values in $h_{M}$ and $h_{N}$ are denoted as in $h_{M}^{\sigma(j)}$ and $h_{N}^{\sigma(j)}$, respectively. They satisfy the following rules:

(i) $0 \leq d\left(h_{M}, h_{N}\right) \leq 1$;

(ii) $d\left(h_{M}, h_{N}\right)=0$ if and only if $h_{M}^{\sigma(j)}=h_{N}^{\sigma(j)}$ for each $j$;

(iii) $d\left(h_{M}, h_{N}\right)=d\left(h_{N}, h_{M}\right)$;

(iv) For three HFEs $h_{M}, h_{N}$, and $h_{F}$ with the same length $l$, if $h_{M}^{\sigma(j)} \leq h_{N}^{\sigma(j)} \leq h_{F}^{\sigma(j)}$ for each $j$, then $d\left(h_{M}, h_{N}\right) \leq d\left(h_{M}, h_{F}\right)$ and $d\left(h_{N}, h_{F}\right) \leq$ $d\left(h_{M}, h_{F}\right)$.

Definition 12 [40]. The interval-valued hesitant fuzzy hamming and interval-valued hesitant fuzzy Euclidean distance measures are represented, respectively, as follows:

$$
\begin{aligned}
d\left(\tilde{h}_{M}, \tilde{h}_{N}\right)= & \frac{1}{2 l_{x_{i}}} \sum_{j=1}^{l_{x_{i}}}\left(\left|\tilde{h}_{M}^{\sigma(j) L}\left(x_{i}\right)-\tilde{h}_{N}^{\sigma(j) L}\left(x_{i}\right)\right|\right. \\
& \left.+\left|\tilde{h}_{M}^{\sigma(j) U}\left(x_{i}\right)-\tilde{h}_{N}^{\sigma(j) U}\left(x_{i}\right)\right|\right), \\
d\left(\tilde{h}_{M}, \tilde{h}_{N}\right)= & \sqrt{\frac{1}{2 l_{x_{i}}} \sum_{j=1}^{l_{x_{i}}}\left(\left|\tilde{h}_{M}^{\sigma(j) L}\left(x_{i}\right)-\tilde{h}_{N}^{\sigma(j) L}\left(x_{i}\right)\right|^{2}\right.} \\
& \left.+\left|\tilde{h}_{M}^{\sigma(j) U}\left(x_{i}\right)-\tilde{h}_{N}^{\sigma(j) U}\left(x_{i}\right)\right|^{2}\right)
\end{aligned}
$$

where $\tilde{h}_{M}$ and $\tilde{h}_{N}$ are the interval-valued HFSs, and the $j$ th largest values in $\tilde{h}_{M}^{L}, \tilde{h}_{M}^{U}, \tilde{h}_{N}^{L}$, and $\tilde{h}_{N}^{U}$ are indicated by $\tilde{h}_{M}^{\sigma(j) L}, \tilde{h}_{M}^{\sigma(j) U}, \tilde{h}_{N}^{\sigma(j) L}$, and $\tilde{h}_{N}^{\sigma(j) U}$, respectively.

Definition 13. The hesitant fuzzy decision matrix $\left(G=\left(g_{i j}\right)_{m \times n}\right)$ could be established to become normalized hesitant fuzzy decision matrix $\left(B=\left(b_{i j}\right)_{m \times n}\right)$ based on the following relations [57]:

$$
\begin{aligned}
b_{i j}=\cup_{t_{i j} \in b_{i j}} \\
= \begin{cases}\left\{\gamma_{i j}\right\} & \text { for positive criteria } \\
& \forall i=1, \ldots, m ; j=1, \ldots, n \\
\left\{1-\gamma_{i j}\right\} & \text { for negative criteria }\end{cases}
\end{aligned}
$$

where $\cup_{t_{i j} \in b_{i j}}\left\{1-\gamma_{i j}\right\}=h^{c}$ is defined as the complement of $h$.

Definition 14. The interval-valued hesitant fuzzy decision matrix could be normalized as follows [58]:

$$
\begin{aligned}
& b_{i j}=\cup_{t_{i j} \in b_{i j}} \\
& = \begin{cases}\left\{\left[\gamma_{i j}^{l}, \gamma_{i j}^{u}\right]\right\} & \text { for positive criteria } \\
\left\{\left[1-\gamma_{i j}^{u}, 1-\gamma_{i j}^{l}\right]\right\} & \text { for negative criteria }\end{cases}
\end{aligned}
$$


where $\cup_{t_{i j} \in b_{i j}}\left[1-\gamma_{i j}^{u}, 1-\gamma_{i j}^{l}\right]=h^{c}$ is defined as the complement of $h$.

Definition 15. $\tilde{M}$ and $\tilde{N}$ are assumed as two intervalvalued hesitant fuzzy sets on $X$. The component-wise ordering and the total ordering are represented as two types of ordering of interval-valued HFSs, respectively, as follows [41]:

$$
\begin{aligned}
& \tilde{M} \leq \tilde{N} \text { if } h_{\tilde{M}}^{\sigma(j) L}\left(x_{i}\right) \leq h_{\tilde{N}}^{\sigma(j) L}\left(x_{i}\right), \\
& h_{\tilde{M}}^{\sigma(j) U}\left(x_{i}\right) \leq h_{\tilde{N}}^{\sigma(j) U}\left(x_{i}\right) \quad \forall i=1,2, \ldots, n ; \\
& \quad j=1,2, \ldots, l_{x_{i}}, \\
& \tilde{M} \prec \tilde{N} \text { if score }(\tilde{M}) \leq \operatorname{score}(\tilde{N}), \\
& \text { Score }(\tilde{M})= \\
& \quad \frac{1}{n} \sum_{i=1}^{n}\left(\frac{1}{l_{x_{i}}} \sum_{j=1}^{l_{x_{i}}}\left[\frac{h_{\tilde{M}}^{\sigma(j) L}\left(x_{i}\right)+h_{\tilde{M}}^{\sigma(j) U}\left(x_{i}\right)}{2}\right]\right),
\end{aligned}
$$

where $h_{M}$ and $h_{N}$ are interval-valued HFSs represented as:

$$
h_{\tilde{M}}^{\sigma(j)}\left(x_{i}\right)=\left[h_{\tilde{M}}^{\sigma(j) L}\left(x_{i}\right), h_{\tilde{M}}^{\sigma(j) U}\left(x_{i}\right)\right],
$$

and:

$$
h_{\tilde{N}}^{\sigma(j)}\left(x_{i}\right)=\left[h_{\tilde{N}}^{\sigma(j) L}\left(x_{i}\right), h_{\tilde{N}}^{\sigma(j) U}\left(x_{i}\right)\right]
$$

respectively; further, $h_{\tilde{M}}^{\sigma(j)}$ and $h_{\tilde{N}}^{\sigma(j)}$ are the $j$ th largest intervals in $h_{\tilde{M}}\left(x_{i}\right)$ and $h_{\tilde{N}}\left(x_{i}\right)$, respectively.

\section{The proposed new hesitant fuzzy group decision model}

In this section, the proposed model is presented based on HFSs theory. Assume $A_{i}(i=1,2, \ldots, m)$ as alternatives, $C_{j}(j=1,2, \ldots, n)$ as criteria, and $k$ as the DMs' index $(k=1,2, \ldots, K)$. In the following, steps of the proposed new hesitant fuzzy group decision model based on new last aggregation complex proportional assessment and compromise solution methods are provided as follows:
Step 1. Determine the most effective criteria, describing the potential alternatives for the evaluation.

Step 2. Specify the hesitant fuzzy decision matrix $(G)$ from a committee of DMs obtained by Eq. (30) as shown in Box I, where $\mu_{i j}^{k}$ expresses the preference value of the $k$ th DM for alternative $i$ under criterion $j$. The aforementioned decision matrix could be developed based on interval-valued hesitant fuzzy information by assigning some interval-values membership degrees according to Definition 3 for potential candidates under each assessment criterion.

Step 3. Determine criteria weights by applying the proposed hesitant fuzzy entropy method regarding DMs' opinions.

The proposed weighting approach to the assessment criteria is established based on two aspects. In the first aspect, the DMs' opinions for determining the criteria are considered in the procedure of the proposed approach to reaching an interactive solution. In the second aspect, the proposed hesitant fuzzy entropy method is manipulated to determine the weights of each criterion based on the dispersion concept. In fact, considering both of the aspects could lead to more reliable results. Amount of uncertainty in case of hesitant fuzzy environment is the concept of the proposed hesitant fuzzy entropy method. The main aim of the proposed approach is that the criterion with higher dispersion has the higher relative significance. However, the process of the proposed hesitant fuzzy entropy method is expressed as follows:

Step 3.1. Aggregate DMs' judgments for rating alternatives and construct the aggregated hesitant fuzzy decision matrix and also aggregate DMs' opinions about relative importance of criteria $\left(v_{j}\right)$ for determining criteria weights by utilizing the following relation based on Definition 8:

$$
\begin{aligned}
v_{j} & =H F G\left(\tilde{h}_{1}, \tilde{h}_{2}, \ldots, \tilde{h}_{k}\right)=\left(\underset{k=1}{\bigoplus}\left(\tilde{h}_{k}\right)^{\frac{1}{k}}\right) \\
& =\cup_{\tilde{\gamma}_{1} \in \tilde{h}_{1}, \tilde{\gamma}_{2} \in \tilde{h}_{2}, \ldots, \tilde{\gamma}_{k} \in \tilde{h}_{k}}\left\{\prod_{j=1}^{K}\left(\gamma_{k}\right)^{\frac{1}{k}}\right\},
\end{aligned}
$$

where $v_{j}$ is the aggregated DMs' judgments about the relative importance of the $j$ th criterion. In

$$
G=\begin{gathered}
A_{1} \\
\vdots \\
A_{m}
\end{gathered}\left[\begin{array}{ccc}
C_{1} & \ldots & C_{n} \\
\left\{\mu_{11}^{1}, \mu_{11}^{2}, \ldots, \mu_{11}^{k}\right\} & \cdots & \left\{\mu_{1 n}^{1}, \mu_{1 n}^{2}, \ldots, \mu_{1 n}^{k}\right\} \\
\vdots & \ddots & \vdots \\
\left\{\mu_{m 1}^{1}, \mu_{m 1}^{2}, \ldots, \mu_{m 1}^{k}\right\} & \cdots & \left\{\mu_{m n}^{1}, \mu_{m n}^{2}, \ldots, \mu_{m n}^{k}\right\}
\end{array}\right]_{m \times n}
$$


the interval-valued hesitant fuzzy environment, the DMs' opinions about evaluating the potential candidates and the relative importance of criteria could be aggregated based on Definition 9 .

Step 3.2. Specify the dispersion index $\left(p_{i j}\right)$ by the following relation if $\mu_{i j} \leq 1-\prod_{i=1}^{m}\left(1-\mu_{i j}\right)$ and $1-\prod_{i=1}^{m}\left(1-\mu_{i j}\right) \neq 0$; otherwise $p_{i j}$ equals zero.

$$
p_{i j}=\frac{\mu_{i j}}{1-\prod_{i=1}^{m}\left(1-\mu_{i j}\right)} \text {. }
$$

The aforementioned relation in the intervalvalued HFSs theory can be considered by upper and lower boundaries regarding Definition 5 .

Step 3.3. Specify the hesitant fuzzy entropy $\left(E_{j}\right)$ for each criterion as follows:

$$
E_{j}=\frac{1}{\sqrt[\operatorname{Ln(m)}]{\prod_{i=1}^{m}\left(1-p_{i j}\right)^{\operatorname{Ln}\left(p_{i j}\right)}}} .
$$

Step 3.4. Specify the unreliability or degree of deviation $\left(d_{j}\right)$ for each criterion as follows:

$$
d_{j}=1-E_{j}
$$

Step 3.5. Determine criteria weights $\left(w_{j}\right)$ regarding judgments of the DMs.

$$
w_{j}=\frac{v_{j} \cdot d_{j}}{\sum_{j=1}^{n} v_{j} \cdot d_{j}}
$$

Thus, the normalized weight of each criterion is determined based on the aforementioned relation and $\sum_{j=1}^{n} w_{j}=1$. The criteria weights are obtained as lower and upper boundaries when the intervalvalued HFSs theory is considered.

Step 4. Specify DMs' weights by considering the proposed hesitant fuzzy compromise solution method. Also, this decision model is capable of developing based on interval-valued hesitant fuzzy information.

Step 4.1. Establish the weighted normalized hesitant fuzzy decision matrix $\left(M_{k}\right)$ for each DM. In addition, the normalized hesitant fuzzy decision matrix is obtained based on Definition 13 .

$$
M_{k}=\begin{gathered}
A_{1} \\
\vdots \\
A_{m}
\end{gathered}\left(\begin{array}{cccc}
C_{1} & C_{2} & \cdots & C_{n} \\
\mu_{11}^{k} & \mu_{12}^{k} & \cdots & \mu_{1 n}^{k} \\
\vdots & \vdots & \ddots & \vdots \\
\mu_{m 1}^{k} & \mu_{m 2}^{k} & \cdots & \mu_{m n}^{k}
\end{array}\right)_{m \times n}
$$

In addition, the decision matrix can be normalized based on Definition 14 in an interval-valued hesitant fuzzy situation, and the normalized interval-valued hesitant fuzzy decision matrix can be established.

Step 4.2. Specify the Hesitant Fuzzy Positive Ideal Solution (HF-PIS) $\left(\delta^{*}\right)$ and Hesitant Fuzzy Negative Ideal Solution (HF-NIS) $\left(\delta^{-}\right)$as follows:

$$
\begin{aligned}
& \delta^{*}=\left(\mu_{i j}^{*}\right)_{m \times n}= \\
& \begin{array}{c}
A_{1} \\
\vdots \\
A_{m}
\end{array}\left(\begin{array}{cccc}
C_{1} & C_{2} & \cdots & C_{n} \\
\mu_{11}^{*} & \mu_{12}^{*} & \cdots & \mu_{1 n}^{*} \\
\vdots & \vdots & \ddots & \vdots \\
\mu_{m 1}^{*} & \mu_{m 2}^{*} & \cdots & \mu_{m n}^{*}
\end{array}\right)_{m \times n}, \\
& \delta^{-}=\left(\mu_{i j}^{-}\right)_{m \times n}= \\
& \begin{array}{c}
A_{1} \\
\vdots \\
A_{m}
\end{array}\left(\begin{array}{cccc}
C_{1} & C_{2} & \cdots & C_{n} \\
\mu_{11}^{-} & \mu_{12}^{-} & \cdots & \mu_{1 n}^{-} \\
\vdots & \vdots & \ddots & \vdots \\
\mu_{m 1}^{-} & \mu_{m 2}^{-} & \cdots & \mu_{m n}^{-}
\end{array}\right)_{m \times n}
\end{aligned}
$$

where the average of group decision matrix is calculated as follows:

$$
\begin{aligned}
& \mu_{i j}^{*}=\frac{1}{K} \sum_{k=1}^{K} \mu_{i j}^{k}, \\
& \mu_{i j}^{-}=\min _{k}\left\{\mu_{i j}^{k}\right\} .
\end{aligned}
$$

Hence, in the case of interval-valued HFSs, the upper and lower boundaries must be defined for positive and negative ideal solutions.

Step 4.3. Compute the separation measure for each hesitant fuzzy decision matrix that is judged by DMs, and the values of HF-PIS $\left(\varphi_{k}^{*}\right)$ and HF-NIS $\left(\varphi_{k}^{-}\right)$are provided by utilizing the hesitant fuzzy Euclidean distance measure, which is provided in Definition 11. In this respect, the hesitant fuzzy Euclidean distance measure is transformed into $n$-dimensional hesitant fuzzy Euclidean distance measure as follows:

$$
\varphi_{k}^{*}=\left[\sum_{i=1}^{m} \sum_{j=1}^{n} \sum_{\lambda=1}^{l_{x_{i}}}\left(\left|\mu_{i j}^{\sigma(\lambda)}\left(x_{i}\right)-\delta_{i j}^{* \sigma(\lambda)}\left(x_{i}\right)\right|^{2}\right)\right]^{\frac{1}{2}}
$$$$
\forall k \text {, }
$$

$\varphi_{k}^{-}=\left[\sum_{i=1}^{m} \sum_{j=1}^{n} \sum_{\lambda=1}^{l_{x_{i}}}\left(\left|\mu_{i j}^{\sigma(\lambda)}\left(x_{i}\right)-\delta_{i j}^{-\sigma(\lambda)}\left(x_{i}\right)\right|^{2}\right)\right]^{\frac{1}{2}}$

$$
\forall k,
$$


Moreover, the separation measures can be calculated based on the interval-valued hesitant fuzzy Euclidean distance measure regarding Definition 12.

Step 4.4. Specify DMs' weights $\left(\psi_{k}\right)$ according to the relative closeness index.

$$
\psi_{k}=\frac{\varphi_{k}^{-}}{\left(\varphi_{k}^{-}+\varphi_{k}^{*}\right) \sum_{k=1}^{K} \frac{\varphi_{k}^{-}}{\varphi_{k}^{-}+\varphi_{k}^{*}}} \quad \forall k .
$$

The DMs' weights are achieved as lower and upper boundaries when the interval-valued HFSs theory is applied in the proposed model. Moreover, the top manager can determine weights of the DMs $\left(\Im_{k}\right)$ regarding their expertise. In this respect, the final DM's weight is determined as in:

$$
\psi_{k}^{f}=\frac{\Im_{k} \psi_{k}}{\sum_{k=1}^{K} \Im_{k} \psi_{k}} \forall k .
$$

Step 5. Compute sum $p_{i}^{k}$ of criteria's values which are the positive criteria for each potential alternative regarding weighted normalized hesitant fuzzy decision matrix for each DM in Step 4.1.

$$
p_{i}^{k}=1-\prod_{j=1}^{l}\left(1-\mu_{i j}\right) \quad \forall k, i,
$$

where $l$ is the number of positive criteria. It is supposed that, in the hesitant fuzzy decision matrix, columns, first of all, are placed by positive criteria, and then they are replaced by negative.

Step 6. Compute sum $R_{i}^{k}$ of criteria's values which are negative criteria for each potential alternative with respect to weighted normalized hesitant fuzzy decision matrix for each DM in Step 4.1.

$$
R_{i}^{k}=1-\prod_{j=l+1}^{n}\left(1-\mu_{i j}\right) \quad \forall k, i .
$$

Step 7. Specify the smallest value of $R_{i}^{k}$ as follows:

$$
R_{\min }^{k}=\min _{i}\left(R_{i}^{k}\right) \quad \forall k \text {. }
$$

Step 8. Compute the relative significance weight of each potential alternative $\left(Q_{i}^{k}\right)$ regarding each DM:

$$
\begin{aligned}
Q_{i}^{k}= & \left(1-P_{i}^{k}\left(\prod_{i}^{m}\left(1-\frac{R_{\min }^{k}}{R_{i}^{k}}\right)\right)^{R_{i}^{k}}\right. \\
& \left.+\left(P_{i}^{k}-1\right)\left(\prod_{i}^{m}\left(1-R_{i}^{k}\right)\right)^{R_{\min }^{k}}\right) \\
& \left(1-\left(\prod_{i}^{m}\left(1-\frac{R_{\min }^{k}}{R_{i}^{k}}\right)\right)^{R_{i}^{k}}\right)^{-1} \forall k, i .
\end{aligned}
$$

The relative importance weight of each potential alternative in the area of interval-valued hesitant fuzzy environment can be presented by lower and upper boundaries regarding Definition 7 .

Step 9. Determine each $Q_{i}$ by utilizing the HFWG operator based on Definition 8 as follows:

$$
\begin{aligned}
Q_{i} & =H F W G\left(Q_{i}^{1}, Q_{i}^{2}, \ldots, Q_{i}^{k}\right)=\underset{k=1}{\otimes}\left(Q_{i}^{k}\right)^{\psi_{k}} \\
& =\cup_{\gamma_{1} \in h_{1}, \gamma_{2} \in h_{2}, \ldots, \gamma_{n} \in h_{n}}\left\{\prod_{k=1}^{K}\left(Q_{i}^{k}\right)^{\psi_{k}}\right\} \forall i
\end{aligned}
$$

In the interval-valued hesitant fuzzy environment, $Q_{i}^{k}$ values can be aggregated using the IVHFWG operator based on Definition 10.

Step 10. Specify the utility degree $\left(N_{i}\right)$ for each alternative.

$$
N_{i}=\frac{Q_{i}}{\max _{i}\left(Q_{i}\right)} .
$$

Step 11. Rank the potential alternatives by the descending order of the utility degrees' values. In addition, to rank the utility degree in the intervalvalued hesitant fuzzy environment, the componentwise ordering and total ordering can be considered and presented according to Definition 15.

\section{Applications of the proposed model}

In this section, the implementation of the proposed hesitant fuzzy group decision model is represented based on a real case study in developing countries. Moreover, an illustrative example is considered to show that the proposed model is reliable and suitable for larger size safety decision problems.

\subsection{Case study: Safety evaluation of construction-project work systems}

The case study about the safety evaluation of construction-project work systems is taken from developing countries to indicate the suitability and feasibility of the proposed new hesitant fuzzy group decision model. In this complex safety decision problem, the safety management in construction industry in Iran is assessed with respect to three alternatives as hydropower construction-project management $\left(A_{1}\right)$, highway construction project management $\left(A_{2}\right)$, and gas refinery construction-project management $\left(A_{3}\right)$ as depicted in Figure 1 under five evaluation criteria $\left(C_{i}, j=1,2, \ldots, 5\right)$. To address this issue, three DMs as professional safety experts $\left(D M_{k}, k=1,2,3\right)$ with a minimum of fifteen years of experience in the construction industry are considered to evaluate 


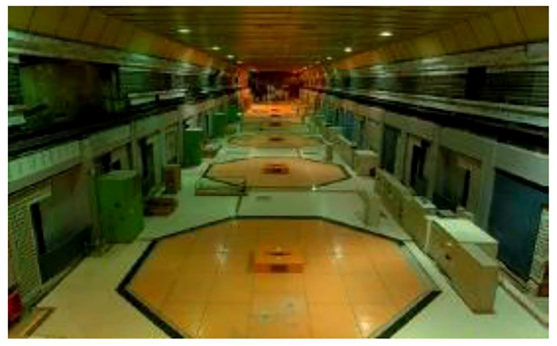

Hydropower construction-project management $\left(A_{1}\right)$

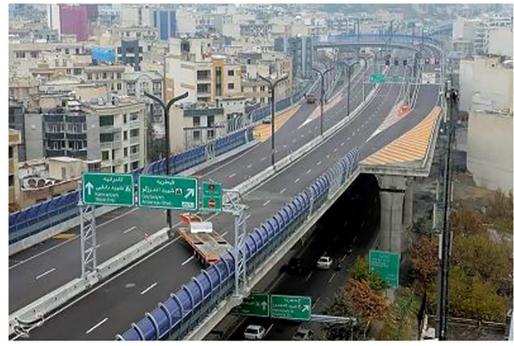

Highway construction-project management $\left(A_{2}\right)$

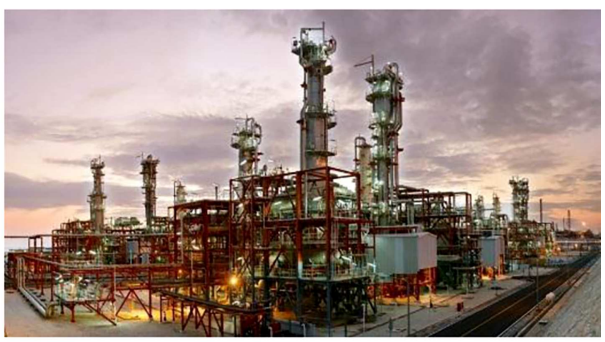

Gas refinery construction-project management $\left(A_{3}\right)$

Figure 1. Potential alternatives in the real case study for the evaluation.

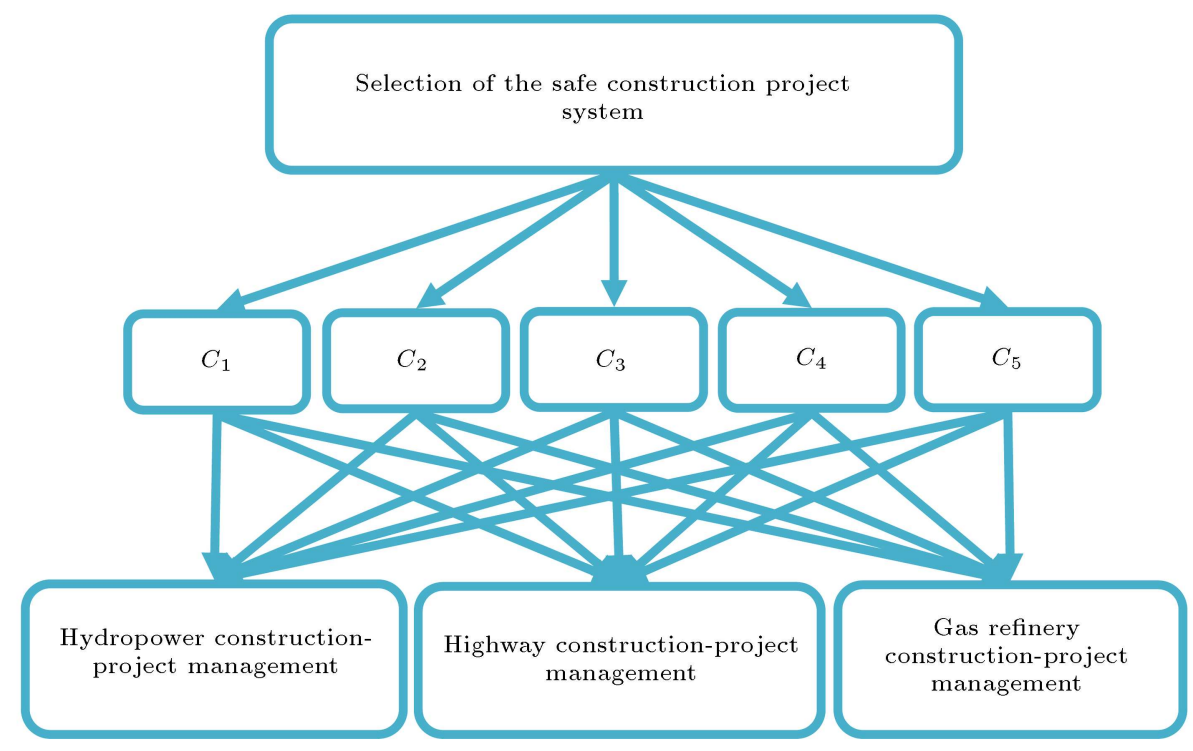

Figure 2. The structure of safety evaluation problem in construction projects.

three project work systems/alternatives $\left(A_{i}, i=1,2,3\right)$ versus the five criteria. The first DM's risk preference is moderate, second one is pessimistic, and the third one is optimistic. The structure of the safety problem is depicted in Figure 2. In addition, for the selection of safe construction project systems, these criteria are described as follows:

- Construction personnel unsafe acts $\left(C_{1}\right)$;

- Occupational health $\left(C_{2}\right)$;

- Technical performance measure $\left(C_{3}\right)$;
- Risk monitoring $\left(C_{4}\right)$;

- Safety construction investment $\left(C_{5}\right)$.

The relative significance of the selected criteria and the evaluation of three alternatives as construction project management are demonstrated by linguistic variables, and their values are provided in Tables 1 and 2 , respectively. In addition, this study considers the risk preferences for professional safety experts, such that $\mathrm{DM}_{1}$ is pessimistic, $\mathrm{DM}_{2}$ is moderate, and $\mathrm{DM}_{3}$ is optimistic. In this respect, the evaluation

Table 1. Linguistic variables for rating the importance of safety assessment criteria.

\begin{tabular}{lcccc}
\hline & & \multicolumn{2}{c}{ Decision makers' risk preferences } \\
\cline { 3 - 5 } Linguistic variables & $\begin{array}{c}\text { Interval-valued hesitant } \\
\text { fuzzy elements }\end{array}$ & Pessimist & Moderate & Optimist \\
\hline Very High (VH) & {$[0.90,0.90]$} & 0.90 & 0.90 & 0.90 \\
High (H) & {$[0.75,0.80]$} & 0.75 & 0.775 & 0.80 \\
Medium (M) & {$[0.50,0.55]$} & 0.50 & 0.525 & 0.55 \\
Low (L) & {$[0.35,0.40]$} & 0.35 & 0.375 & 0.40 \\
Very Low (VL) & {$[0.10,0.10]$} & 0.10 & 0.10 & 0.10 \\
\hline
\end{tabular}


Table 2. Linguistic variables for rating the possible alternatives.

\begin{tabular}{lcccc}
\hline & & \multicolumn{2}{c}{ Decision } & makers' risk preferences \\
\cline { 3 - 5 } Linguistic variables & $\begin{array}{c}\text { Interval-valued hesitant } \\
\text { fuzzy elements }\end{array}$ & Pessimist & Moderate & Optimist \\
\hline Extremely Good (EG) & {$[1.00,1.00]$} & 1 & 1 & 1 \\
Very Very Good (VVG) & {$[0.90,0.90]$} & 0.90 & 0.90 & 0.90 \\
Very Good (VG) & {$[0.80,0.90]$} & 0.80 & 0.85 & 0.90 \\
Good (G) & {$[0.70,0.80]$} & 0.70 & 0.75 & 0.80 \\
Moderately Good (MG) & {$[0.60,0.70]$} & 0.60 & 0.65 & 0.70 \\
Moderate (M) & {$[0.50,0.60]$} & 0.50 & 0.55 & 0.60 \\
Moderately Poor (MP) & {$[0.40,0.50]$} & 0.40 & 0.45 & 0.50 \\
Poor (P) & {$[0.25,0.40]$} & 0.25 & 0.325 & 0.40 \\
Very Poor (VP) & {$[0.10,0.25]$} & 0.10 & 0.175 & 0.25 \\
Very Very Poor (VVP) & {$[0.10,0.10]$} & 0.10 & 0.10 & 0.10 \\
\hline
\end{tabular}

Table 3. Performance ratings of three project work systems/alternatives in linguistic variables for the case study.

\begin{tabular}{|c|c|c|c|c|}
\hline \multirow[b]{2}{*}{ Criteria } & \multirow[b]{2}{*}{ Alternatives } & \multicolumn{3}{|c|}{ Decision makers } \\
\hline & & $D M_{1}$ & $D M_{2}$ & $D M_{3}$ \\
\hline \multirow{3}{*}{$\begin{array}{l}\text { Construction personnel } \\
\text { unsafe acts }\left(C_{1}\right)\end{array}$} & $A_{1}$ & $\mathrm{MG}$ & $\mathrm{M}$ & MP \\
\hline & $A_{2}$ & MP & $\mathrm{P}$ & $\mathrm{P}$ \\
\hline & $A_{3}$ & $\mathrm{G}$ & $\mathrm{G}$ & VG \\
\hline \multirow{3}{*}{ Occupational health $\left(C_{2}\right)$} & $A_{1}$ & $\mathrm{P}$ & M & M \\
\hline & $A_{2}$ & VG & G & G \\
\hline & $A_{3}$ & MG & M & M \\
\hline \multirow{3}{*}{$\begin{array}{c}\text { Technical performance } \\
\text { measure }\left(C_{3}\right)\end{array}$} & $A_{1}$ & $\mathrm{M}$ & M & $\mathrm{MP}$ \\
\hline & $A_{2}$ & VP & $\mathrm{P}$ & MP \\
\hline & $A_{3}$ & $\mathrm{G}$ & G & MG \\
\hline \multirow{3}{*}{ Risk monitoring $\left(C_{4}\right)$} & $A_{1}$ & MG & $\mathrm{M}$ & G \\
\hline & $A_{2}$ & VVG & VG & VG \\
\hline & $A_{3}$ & VG & G & MG \\
\hline \multirow{3}{*}{$\begin{array}{l}\text { Safety construction } \\
\text { investment }\left(C_{5}\right)\end{array}$} & $A_{1}$ & G & G & VG \\
\hline & $A_{2}$ & VP & $\mathrm{P}$ & MP \\
\hline & $A_{3}$ & G & VG & VG \\
\hline
\end{tabular}

of alternatives among conflicting criteria is expressed by judgments (preferences) of the DMs with linguistic variables. This decision matrix is converted by the HFEs; the results are provided in Tables 3 and 4. Also, weights of criteria as well as the evaluation of potential alternatives (i.e., construction project management) are determined. The importance of each criterion is defined by linguistic variables; then, these linguistic terms are transformed to the HFEs that are represented in Tables 5 and 6 , respectively.

The weights of criteria are determined by the proposed hesitant fuzzy-entropy method. In this regard, the hesitant fuzzy decision matrixes that are established by each DM are aggregated. In addition, $p_{i j}$ matrix is constructed by utilizing Eq. (32). Then, the degree of deviation/un reliability of each criterion is computed with respect to the hesitant fuzzy entropy method based on Eqs. (33) and (34). Finally, the weight of each criterion is specified by applying the DMs' opinions about the relative importance of safety assessment criteria. The computational results are demonstrated in Table 7 . Also, the weight of each $\mathrm{DM}$ is determined by the proposed hesitant fuzzy compromise solution method. As a result, the hesitant 
Table 4. Performance ratings of three alternatives by the HFEs for the case study.

\begin{tabular}{ccccc}
\hline \multirow{2}{*}{ Criteria } & & \multicolumn{3}{c}{ Decision makers } \\
\cline { 3 - 5 } & Alternatives & $\boldsymbol{D} \boldsymbol{M}_{\mathbf{1}}$ & $\boldsymbol{D} \boldsymbol{M}_{\mathbf{2}}$ & $\boldsymbol{D} \boldsymbol{M}_{\mathbf{3}}$ \\
\hline \multirow{2}{*}{ Construction personnel } & $A_{1}$ & 0.60 & 0.55 & 0.50 \\
unsafe acts $\left(C_{1}\right)$ & $A_{2}$ & 0.40 & 0.325 & 0.40 \\
& $A_{3}$ & 0.70 & 0.75 & 0.90 \\
Occupational health $\left(C_{2}\right)$ & & & & \\
& $A_{1}$ & 0.25 & 0.55 & 0.60 \\
Technical performance & $A_{2}$ & 0.80 & 0.75 & 0.80 \\
measure $\left(C_{3}\right)$ & $A_{3}$ & 0.60 & 0.55 & 0.60 \\
& & & & \\
Risk monitoring $\left(C_{4}\right)$ & $A_{1}$ & 0.50 & 0.55 & 0.50 \\
& $A_{2}$ & 0.10 & 0.325 & 0.50 \\
Safety construction & $A_{3}$ & 0.70 & 0.75 & 0.70 \\
investment $\left(C_{5}\right)$ & & & & \\
& $A_{1}$ & 0.60 & 0.55 & 0.80 \\
& $A_{2}$ & 0.90 & 0.85 & 0.90 \\
& $A_{3}$ & 0.80 & 0.75 & 0.70 \\
& & & & \\
& $A_{1}$ & 0.70 & 0.75 & 0.90 \\
& $A_{2}$ & 0.10 & 0.325 & 0.50 \\
& $A_{3}$ & 0.70 & 0.85 & 0.90 \\
\hline
\end{tabular}

Table 5. The preference of decision-makers' judgments about criteria weights by linguistic terms for the case study.

\begin{tabular}{cccc}
\hline & \multicolumn{3}{c}{ Decision makers } \\
\cline { 2 - 4 } Criteria & $\boldsymbol{D} \boldsymbol{M}_{\mathbf{1}}$ & $\boldsymbol{D} \boldsymbol{M}_{\mathbf{2}}$ & $\boldsymbol{D} \boldsymbol{M}_{\mathbf{3}}$ \\
\hline$C_{1}$ & $\mathrm{H}$ & $\mathrm{VH}$ & $\mathrm{VH}$ \\
$C_{2}$ & $\mathrm{VH}$ & $\mathrm{H}$ & $\mathrm{VH}$ \\
$C_{3}$ & $\mathrm{M}$ & $\mathrm{L}$ & $\mathrm{M}$ \\
$C_{4}$ & $\mathrm{VH}$ & $\mathrm{VH}$ & $\mathrm{H}$ \\
$C_{5}$ & $\mathrm{VH}$ & $\mathrm{H}$ & $\mathrm{H}$ \\
\hline
\end{tabular}

Table 6. The preference of decision-makers' judgments about criteria weights by the HFEs for the case study.

\begin{tabular}{cccc}
\hline & \multicolumn{3}{c}{ Decision makers } \\
\cline { 2 - 4 } Criteria & $\boldsymbol{D} \boldsymbol{M}_{\mathbf{1}}$ & $\boldsymbol{D} \boldsymbol{M}_{\mathbf{2}}$ & $\boldsymbol{D} \boldsymbol{M}_{\mathbf{3}}$ \\
\hline$C_{1}$ & 0.775 & 0.90 & 0.90 \\
$C_{2}$ & 0.90 & 0.75 & 0.90 \\
$C_{3}$ & 0.525 & 0.35 & 0.55 \\
$C_{4}$ & 0.90 & 0.90 & 0.80 \\
$C_{5}$ & 0.90 & 0.75 & 0.80 \\
\hline
\end{tabular}

fuzzy decision matrix is normalized for each DM based on definition 13. Then, the HF-PIS and HF-NIS are determined by utilizing Eqs. (37)-(40). Then, the separation measures are calculated based on ndimensional hesitant fuzzy Euclidean distance measure. Finally, the DMs' weights are obtained by Eq. (43). The results of the proposed hesitant fuzzy compromise solution method for determining the weight of each DM as professional safety expert are illustrated in Table 8.
After computing the weights of criteria and DMs, this study considers the following steps to rank and select the best potential alternatives as safe construction-project work systems. Thus, the sums of positive/negative criteria values $\left(p_{i}^{k} / R_{i}^{k}\right)$ are calculated with respect to weighted normalized hesitant fuzzy decision matrix of each DM using Eqs. (44) and (45). Then, the smallest values of $R_{i}^{k}$ are specified. The results are presented in Tables 9 and 10; hence, the relative significance weight of each alternative according to each DM is calculated by utilizing Eq. (47) and is shown in Table 11. Finally, as indicated in Table 12, this study aggregates the relative significance weights by applying the HFWG operator to determine the utility degree. In this respect, the potential alternatives are ranked and the construction projects work systems are selected based on utility degrees' values in descending order.

The proposed new hesitant fuzzy group decision model is powerful and capable to cope with imprecise/uncertain conditions in the project safety management. It is because that the DMs as professional safety experts have assigned their preferences' values to an object under a set to decrease errors. In addition, within group decision-making process, the DMs' opinions are aggregated in the last step to decrease the loss of information. Also, the presented model has applied weights of the DMs and criteria in the group decisionmaking process by three new versions of the complex proportional assessment, compromise solution, and entropy methods under the hesitant fuzzy environment. As demonstrated in Table 12, the third construction project is selected as the best project from the safety 
Table 7. Computational results of the proposed hesitant fuzzy entropy method for estimating safety criteria weights for the case study.

\begin{tabular}{|c|c|c|c|c|c|}
\hline \multirow[b]{2}{*}{ Alternatives } & \multicolumn{5}{|c|}{ Aggregated hesitant fuzzy decision matrix } \\
\hline & $C_{1}$ & $C_{2}$ & $C_{3}$ & $C_{4}$ & $C_{5}$ \\
\hline$A_{1}$ & 0.54848 & 0.43533 & 0.51614 & 0.64151 & 0.77887 \\
\hline$A_{2}$ & 0.37325 & 0.78297 & 0.25329 & 0.88301 & 0.25329 \\
\hline \multirow[t]{2}{*}{$A_{3}$} & 0.77887 & 0.58285 & 0.71628 & 0.74889 & 0.81206 \\
\hline & \multicolumn{5}{|c|}{ The $P_{i j}$ matrix } \\
\hline Alternatives & $C_{1}$ & $C_{2}$ & $C_{3}$ & $C_{4}$ & $C_{5}$ \\
\hline$A_{1}$ & 0.58509 & 0.45878 & 0.57509 & 0.64833 & 0.80382 \\
\hline$A_{2}$ & 0.39817 & 0.82516 & 0.28222 & 0.89241 & 0.26140 \\
\hline \multirow[t]{3}{*}{$A_{3}$} & 0.83087 & 0.61425 & 0.79810 & 0.75686 & 0.83806 \\
\hline & \multicolumn{5}{|c|}{ The $E_{j}, d_{j}, v_{j}$, and $w_{j}$} \\
\hline & $E_{1}$ & $E_{2}$ & $E_{3}$ & $E_{4}$ & $E_{5}$ \\
\hline$E_{j}$ & 0.31521 & 0.31253 & 0.31941 & 0.36722 & 0.37286 \\
\hline \multirow{3}{*}{$d_{j}$} & $d_{1}$ & $d_{2}$ & $d_{3}$ & $d_{4}$ & $d_{5}$ \\
\hline & 0.68479 & 0.68747 & 0.68059 & 0.63278 & 0.62714 \\
\hline & $v_{1}$ & $v_{2}$ & $v_{3}$ & $v_{4}$ & $v_{5}$ \\
\hline \multirow[t]{2}{*}{$v_{j}$} & 0.85624 & 0.84693 & 0.46580 & 0.86535 & 0.81433 \\
\hline & $w_{1}$ & $w_{2}$ & $w_{3}$ & $\boldsymbol{w}_{4}$ & $w_{5}$ \\
\hline$w_{j}$ & 0.23049 & 0.22888 & 0.12462 & 0.21525 & 0.20075 \\
\hline
\end{tabular}

Table 8. Computational results for determining the decision-makers' weights for the case study.

\begin{tabular}{cccc}
\hline Decision-makers & $\boldsymbol{\varphi}_{\boldsymbol{k}}^{*}$ & $\boldsymbol{\varphi}_{\boldsymbol{k}}^{-}$ & $\boldsymbol{\psi}_{\boldsymbol{k}}$ \\
\hline$D M_{1}$ & 0.08080 & 0.09611 & 0.29460 \\
$D M_{2}$ & 0.03642 & 0.07777 & 0.36931 \\
$D M_{3}$ & 0.07687 & 0.12530 & 0.33609 \\
\hline
\end{tabular}

Table 9. $P_{i}$ value regarding each decision-maker for the case study.

\begin{tabular}{cccc}
\hline & $\boldsymbol{D M}_{\mathbf{1}}$ & $\boldsymbol{D} \boldsymbol{M}_{\mathbf{2}}$ & $\boldsymbol{D} \boldsymbol{M}_{\mathbf{3}}$ \\
\hline$P_{1}$ & 0.29817 & 0.30246 & 0.36403 \\
$P_{2}$ & 0.21976 & 0.26721 & 0.31986 \\
$P_{3}$ & 0.35060 & 0.36953 & 0.36484 \\
\hline
\end{tabular}

Table 10. $R_{i}$ value regarding each decision-maker for the case study.

\begin{tabular}{cccc}
\hline & $\boldsymbol{D} \boldsymbol{M}_{\mathbf{1}}$ & $\boldsymbol{D} \boldsymbol{M}_{\mathbf{2}}$ & $\boldsymbol{D} \boldsymbol{M}_{\mathbf{3}}$ \\
\hline$A_{1}$ & 0.24803 & 0.19603 & 0.19625 \\
$A_{2}$ & 0.17774 & 0.20390 & 0.17774 \\
$A_{3}$ & 0.15437 & 0.15468 & 0.11249 \\
$R_{\text {min }}$ & 0.15437 & 0.15468 & 0.11249 \\
\hline
\end{tabular}

point of view among the potential alternatives in the project management versus the safety criteria for the evaluation. Moreover, to determine the validity of the proposed model, the case study is solved by Zhang
Table 11. Final $Q_{i}$ value regarding each decision-maker for the case study.

\begin{tabular}{ccccc}
\hline & $\boldsymbol{D M}_{\mathbf{1}}$ & $\boldsymbol{D M}_{\mathbf{2}}$ & $\boldsymbol{D} \boldsymbol{M}_{\mathbf{3}}$ & Final $\boldsymbol{Q}_{\boldsymbol{i}}$ \\
\hline$Q_{1}$ & 0.36502 & 0.36569 & 0.40107 & 0.37701 \\
$Q_{2}$ & 0.29408 & 0.33363 & 0.35947 & 0.32962 \\
$Q_{3}$ & 0.41245 & 0.42668 & 0.40183 & 0.41401 \\
\hline
\end{tabular}

and Wei's method [59], which is an extension of the TOPSIS method under the hesitant fuzzy environment. As demonstrated in Table 12, the same ranking results derived from the comparison of both decision methods are obtained. The computational results demonstrate that the proposed group decision model works appropriately.

\subsection{Illustrative example: Safety project selection problem}

In this section, an illustrative example about the safety project selection problem is provided to show that the proposed hesitant fuzzy group decision model works properly for larger size safety decision problems. In this respect, eight candidate projects $\left(P_{i}, i=1,2, . ., 8\right)$ are evaluated under five conflicting criteria, including unsafe acts of construction personnel $\left(C_{1}\right)$, occupational health $\left(C_{2}\right)$, technical performance measure $\left(C_{3}\right)$, risk monitoring $\left(C_{4}\right)$, and safety construction investment $\left(C_{5}\right)$, based on the preferences of three DMs $\left(D M_{k}, k=1,2,3\right)$. The first and second DMs' risk 
Table 12. The utility degree and comparative analysis for the case study.

\begin{tabular}{cccccc}
\hline Alternatives & Final $\boldsymbol{Q}_{\boldsymbol{i}}$ & $\boldsymbol{N}_{\boldsymbol{i}}$ & $\begin{array}{c}\text { Ranked by the } \\
\text { proposed hesitant fuzzy } \\
\text { decision model }\end{array}$ & $\begin{array}{c}\text { Hesitant fuzzy } \\
\text { relative closeness }\end{array}$ & $\begin{array}{c}\text { Ranked by Zhang } \\
\text { and Wei's } \\
\text { method [59] }\end{array}$ \\
\hline$A_{1}$ & 0.37701 & $91.07 \%$ & 2 & 0.66704 & 2 \\
$A_{2}$ & 0.32962 & $79.62 \%$ & 3 & 0.60344 & 1 \\
$A_{3}$ & 0.41401 & $100 \%$ & 1 & 0.74229 & 1 \\
$\operatorname{Max}\left(Q_{i}\right)$ & 0.41401 & & & & \\
\hline
\end{tabular}

Table 13. Performance ratings of three project work systems/alternatives in linguistic variables for illustrative example.

\begin{tabular}{|c|c|c|c|c|}
\hline & & De & ion $\mathrm{m}$ & zers \\
\hline Criteria & Alternatives & $D M_{1}$ & $D M_{2}$ & $D M_{3}$ \\
\hline & $P_{1}$ & $\mathrm{VG}$ & $\mathrm{G}$ & $\mathrm{G}$ \\
\hline & $P_{2}$ & $\mathrm{G}$ & $\mathrm{G}$ & G \\
\hline & $P_{3}$ & $\mathrm{G}$ & MG & G \\
\hline Construction personnel & $P_{4}$ & $\mathrm{M}$ & MP & $\mathrm{P}$ \\
\hline unsafe $\operatorname{acts}\left(C_{1}\right)$ & $P_{5}$ & VVG & VG & VG \\
\hline & $P_{6}$ & G & $\mathrm{G}$ & MG \\
\hline & $P_{7}$ & M & $\mathrm{G}$ & $\mathrm{M}$ \\
\hline & $P_{8}$ & G & MG & G \\
\hline & $P_{1}$ & $\mathrm{P}$ & $\mathrm{P}$ & VP \\
\hline & $P_{2}$ & $\mathrm{P}$ & $\mathrm{M}$ & MP \\
\hline & $P_{3}$ & $\mathrm{G}$ & MG & MG \\
\hline & $P_{4}$ & $\mathrm{MG}$ & MG & $\mathrm{G}$ \\
\hline Occupational health $\left(C_{2}\right)$ & $P_{5}$ & $\mathrm{M}$ & MP & MP \\
\hline & $P_{6}$ & $\mathrm{G}$ & MG & G \\
\hline & $P_{7}$ & VP & $\mathrm{P}$ & VVP \\
\hline & $P_{8}$ & $\mathrm{G}$ & MG & G \\
\hline & $P_{1}$ & VVG & MG & $\mathrm{G}$ \\
\hline & $P_{2}$ & VVG & VG & VG \\
\hline & $P_{3}$ & $\mathrm{M}$ & $\mathrm{G}$ & $\mathrm{M}$ \\
\hline Technical performance & $P_{4}$ & MG & $\mathrm{M}$ & MG \\
\hline measure $\left(C_{3}\right)$ & $P_{5}$ & $\mathrm{VP}$ & MP & MP \\
\hline & $P_{6}$ & $\mathrm{P}$ & $\mathrm{P}$ & MP \\
\hline & $P_{7}$ & VG & $\mathrm{G}$ & $\mathrm{G}$ \\
\hline & $P_{8}$ & $\mathrm{M}$ & M & MG \\
\hline & $P_{1}$ & MP & $\mathrm{M}$ & $\mathrm{P}$ \\
\hline & $P_{2}$ & VP & MP & MP \\
\hline & $P_{3}$ & MG & $\mathrm{G}$ & MG \\
\hline & $P_{4}$ & $\mathrm{P}$ & MP & MP \\
\hline Risk monitoring $\left(C_{4}\right)$ & $P_{5}$ & $\mathrm{M}$ & $\mathrm{G}$ & $\mathrm{M}$ \\
\hline & $P_{6}$ & MG & MG & $\mathrm{M}$ \\
\hline & $P_{7}$ & $\mathrm{G}$ & MG & VG \\
\hline & $P_{8}$ & $\mathrm{MG}$ & MG & $\mathrm{M}$ \\
\hline & $P_{1}$ & G & VVG & G \\
\hline & $P_{2}$ & MG & $\mathrm{MG}$ & $\mathrm{G}$ \\
\hline & $P_{3}$ & $\mathrm{G}$ & $\mathrm{VG}$ & $\mathrm{VG}$ \\
\hline Safety construction & $P_{4}$ & $\mathrm{MG}$ & $\mathrm{G}$ & $\mathrm{MG}$ \\
\hline investment $\left(C_{5}\right)$ & $P_{5}$ & VG & $\mathrm{G}$ & G \\
\hline & $P_{6}$ & VVG & VG & VG \\
\hline & $P_{7}$ & G & $\mathrm{VG}$ & $\mathrm{G}$ \\
\hline & $P_{8}$ & $\mathrm{G}$ & MG & $\mathrm{G}$ \\
\hline
\end{tabular}

preference is moderate and the third one is optimistic. In this regard, the hesitant fuzzy decision matrix and the relative importance of each criterion, which are evaluated by the DMs, are reported in Tables 13 and 14 .

The weights of each criterion are computed by applying the proposed hesitant fuzzy entropy method with respect to the DMs' opinions about the relative significance of criteria. Accordingly, the preferences of the DMs are aggregated based on Step 3.1, and then the final weight of each criterion is obtained 
Table 14. The preference of decision-makers' judgments about criteria weights by linguistic terms for illustrative example.

\begin{tabular}{cccc}
\hline & \multicolumn{3}{c}{ Decision makers } \\
\cline { 2 - 4 } Criteria & $\boldsymbol{D} \boldsymbol{M}_{\mathbf{1}}$ & $\boldsymbol{D} \boldsymbol{M}_{\mathbf{2}}$ & $\boldsymbol{D} \boldsymbol{M}_{\mathbf{3}}$ \\
\hline$C_{1}$ & $\mathrm{VH}$ & $\mathrm{H}$ & $\mathrm{VH}$ \\
$C_{2}$ & $\mathrm{H}$ & $\mathrm{M}$ & $\mathrm{H}$ \\
$C_{3}$ & $\mathrm{VH}$ & $\mathrm{H}$ & $\mathrm{H}$ \\
$C_{4}$ & $\mathrm{VH}$ & $\mathrm{H}$ & $\mathrm{VH}$ \\
$C_{5}$ & $\mathrm{H}$ & $\mathrm{VH}$ & $\mathrm{VH}$ \\
\hline
\end{tabular}

Table 15. Computational results of the proposed hesitant fuzzy entropy method for computing safety criteria weights for illustrative example.

\begin{tabular}{ccc}
\hline Criteria & $\boldsymbol{v}_{\boldsymbol{j}}$ & $\boldsymbol{w}_{\boldsymbol{j}}$ \\
\hline$C_{1}$ & 0.85624 & 0.21819 \\
$C_{2}$ & 0.68041 & 0.17406 \\
$C_{3}$ & 0.82327 & 0.20850 \\
$C_{4}$ & 0.85624 & 0.20161 \\
$C_{5}$ & 0.84693 & 0.19764 \\
\hline
\end{tabular}

Table 16. Computational results for determining the decision-makers' weights for illustrative example.

\begin{tabular}{cccc}
\hline Decision makers & $\boldsymbol{\varphi}_{\boldsymbol{k}}^{*}$ & $\boldsymbol{\varphi}_{\boldsymbol{k}}^{-}$ & $\boldsymbol{\psi}_{\boldsymbol{k}}$ \\
\hline$D M_{1}$ & 0.05644 & 0.11038 & 0.339391 \\
$D M_{2}$ & 0.06037 & 0.09467 & 0.313203 \\
$D M_{3}$ & 0.03976 & 0.08345 & 0.347406 \\
\hline
\end{tabular}

with respect to the procedure of the proposed hesitant fuzzy entropy method. The results are reported in Table 15. Moreover, the weights of three DMs are determined based on the proposed hesitant fuzzy compromise solution method. In this regard, the hesitant fuzzy decision matrix is established based on the DMs' judgments, and then the HF-PIS and HF-NIS matrixes are calculated based on Step 4.2. Finally, according to the relative closeness index, the weight of each DM is obtained by computing the separation measures based on Steps 4.3 and 4.4. The aforementioned results are given in Table 16 .

In the following, the procedure of the proposed hesitant fuzzy complex proportional assessment method is considered to rank the candidate projects. However, the relative significance weight of each potential alternative is calculated based on Step 8, and then each $Q_{i}^{k}$ value is aggregated based on the HFWG operator according to the DMs' weights (Step 9). Finally, the utility degree for each potential candidate is determined based on Step 10. The aforementioned results are provided in Tables 17 and 18, respectively. In addition, the illustrative example is solved by Zhang and Wei's method [59], and then the same ranking
Table 17. Final $Q_{i}$ value regarding each decision-maker for illustrative example.

\begin{tabular}{ccccc}
\hline & $\boldsymbol{D M}_{\mathbf{1}}$ & $\boldsymbol{D} \boldsymbol{M}_{\mathbf{2}}$ & $\boldsymbol{D} \boldsymbol{M}_{\mathbf{3}}$ & Final $\boldsymbol{Q}_{\boldsymbol{i}}$ \\
\hline$Q_{1}$ & 0.37841 & 0.35943 & 0.36609 & 0.36811 \\
$Q_{2}$ & 0.36828 & 0.39762 & 0.30238 & 0.35225 \\
$Q_{3}$ & 0.52845 & 0.53674 & 0.52011 & 0.52811 \\
$Q_{4}$ & 0.24487 & 0.21506 & 0.23655 & 0.23231 \\
$Q_{5}$ & 0.28365 & 0.31793 & 0.33112 & 0.31021 \\
$Q_{6}$ & 0.40349 & 0.38973 & 0.41346 & 0.40252 \\
$Q_{7}$ & 0.37446 & 0.42007 & 0.39563 & 0.39567 \\
$Q_{8}$ & 0.46354 & 0.43871 & 0.44611 & 0.44958 \\
\hline
\end{tabular}

results are observed based on both decision methods; these computational results approve the reliability and suitability of the proposed model for larger size safety problems.

As indicated in Table 18, the same ranking results are obtained from both of the proposed model and Zhang and Wei's method [59]. In this regard, the proposed model can perform appropriately due to some main merits and competencies that are considered in the process of the proposed hesitant fuzzy group decision model. Accordingly, in the proposed model, a complex proportional assessment method is developed based on the last aggregation to reduce the data loss for the ranking process. In addition, the weights of each criterion and DM are obtained based on an extended hesitant fuzzy entropy method and a new version of hesitant fuzzy compromise solution method, respectively. Moreover, the risk preferences of the DMs are considered in the procedure of evaluating the group decision-making problem to decrease the assessment error.

\section{Conclusions and future studies}

Safety is an important issue for different projects in the construction industry pragmatically and conceptually. In this respect, this study has proposed a new decision model based on the last aggregation to evaluate safety in construction projects with hesitant fuzzy setting under group decision analysis. In the proposed model, some Decision-Makers (DMs) or professional safety experts' opinions have been provided to evaluate construction project systems as potential alternatives among the conflicting safety assessment criteria. However, because of some merits and features, the proposed hesitant fuzzy decision model is more powerful than the classical fuzzy methods. In this regard, DMs' judgments have been expressed by hesitant linguistic terms transformed into hesitant fuzzy elements. Also, the DMs could assign their opinions by some membership degrees to an object among the safety criteria to decrease errors. Opinions of the DMs 
Table 18. The utility degree and comparative analysis for illustrative example.

\begin{tabular}{cccccc}
\hline Candidates & Final $\boldsymbol{Q}_{\boldsymbol{i}}$ & $\boldsymbol{N}_{\boldsymbol{i}}$ & $\begin{array}{c}\text { Ranked by proposed } \\
\text { hesitant fuzzy decision } \\
\text { model }\end{array}$ & $\begin{array}{c}\text { Hesitant fuzzy } \\
\text { relative closeness }\end{array}$ & $\begin{array}{c}\text { Ranked by Zhang } \\
\text { and Wei's } \\
\text { method [59] }\end{array}$ \\
\hline$P_{1}$ & 0.36811 & $69.71 \%$ & 5 & 0.641573 & 5 \\
$P_{2}$ & 0.35225 & $66.71 \%$ & 6 & 0.640136 & 6 \\
$P_{3}$ & 0.52811 & $100 \%$ & 1 & 0.717071 & 1 \\
$P_{4}$ & 0.23231 & $43.98 \%$ & 8 & 0.581826 & 7 \\
$P_{5}$ & 0.31021 & $58.73 \%$ & 7 & 0.639732 & 3 \\
$P_{6}$ & 0.40252 & $76.22 \%$ & 3 & 0.667435 & 4 \\
$P_{7}$ & 0.39567 & $74.92 \%$ & 4 & 0.645749 & 2 \\
$P_{8}$ & 0.44958 & $85.13 \%$ & 2 & 0.682852 & \\
$M$
\end{tabular}

have been aggregated in the final step of group decision process to reduce the loss of data. A new version of the complex proportional assessment method has been introduced to rank potential safety alternatives with the last aggregation to decrease the loss of data. Hence, weights of the DMs and criteria have been presented by the procedure of the two proposed new versions of weighting methods based on hesitant fuzzy compromise solution and entropy methods. Then, a case study in developing countries has been presented about the evaluation of the construction project systems from the safety point of view to show the efficiency and suitability of the proposed hesitant fuzzy group decision model. In this problem, the gas refinery construction-project management has been selected as the safe project system among the candidate construction-project systems. In addition, an illustrative example was considered to indicate that the proposed approach can properly work for larger size safety problems. Moreover, the obtained results obtained from the proposed model were compared with those of an extended hesitant fuzzy TOPSIS method from the recent literature to confirm the validity and applicability of the proposed model. For future studies, the interval-valued hesitant fuzzy sets as expressed in the process of the proposed model can be considered under uncertain conditions for the development. In complex situations, determining the exact membership degrees by DMs is difficult. Thus, the interval-valued hesitant fuzzy sets can help them express their preferences and opinions by some interval values for an object under a set to reduce the errors. Indeed, the interval-valued hesitant fuzzy sets can be considered in the procedure of the proposed ranking method and in the process of determining the weights of criteria as well as experts. Furthermore, the proposed approach in this study can be implemented and investigated for any type of decision-making problems, such as plant location selection, distribution center location selection, new product development assessment, general contractor selection, and construction project evaluation.

\section{Acknowledgments}

The authors express their gratitude to four anonymous reviewers for their valuable comments and suggestions on the study.

\section{References}

1. Janic, M. "An assessment of risk and safety in civil aviation", Journal of Air Transport Management, 6(1), pp. $43-50$ (2000).

2. Odegard, S. "Safety management in civil aviation: A useful method for improved safety in medical care", Safety Science Monitor, 4(1), pp. 1-12 (2000).

3. Malekly, H., Mousavi, S.M., and Hashemi, H. "A fuzzy integrated methodology for evaluating conceptual bridge design", Expert Systems with Applications, 37(7), pp. 4910-4920 (2010).

4. Bailey, N. "Risk perception and safety management systems in the global maritime industry", Policy and Practice in Health and Safety, 4(2), pp. 59-75 (2006).

5. Bhattacharya, S., Impact of the ISM Code on the Management of Occupational Health and Safety in the Maritime Industry, Cardiff University (2009).

6. Horlick-Jones, T. "Reasoning about safety management policy in everyday terms: a pilot study in citizen engagement for the UK railway industry", Journal of Risk Research, 11(6), pp. 697-718 (2008).

7. Kudla, N. and Majumdar, A., Developing and Testing Model of Data Quality for Safety Management Information Systems: Exploratory Study in British Railway Industry, in Transportation Research Board, 92nd Annual Meeting (2013).

8. Mousavi, S.M., Mirdamadi, S., Siadat, A., Dantan, J., and Tavakkoli-Moghaddam, R. "An intuitionistic fuzzy grey model for selection problems with an application 
to the inspection planning in manufacturing firms", Engineering Applications of Artificial Intelligence, 39, pp. $157-167$ (2015).

9. Vahdani, B., Mousavi, S.M., and TavakkoliMoghaddam, R. "Group decision making based on novel fuzzy modified TOPSIS method", Applied Mathematical Modelling, 35(9), pp. 4257-4269 (2011).

10. Vahdani, B., Mousavi, S.M., Tavakkoli-Moghaddam, R., Ghodratnama, A., and Mohammadi, M. "Robot selection by a multiple criteria complex proportional assessment method under an interval-valued fuzzy environment", International Journal of Advanced Manufacturing Technology, 73(5-8), pp. 687-697 (2014).

11. XIAO-ming, W. and LIU, X.-Y. "Safety system management and safety information management in major transportation construction projects", Safety and Environmental Engineering, 3, p. 015 (2011).

12. Guo, H., Li, H., and Li, V. "VP-based safety management in large-scale construction projects: A conceptual framework", Automation in Construction, 34, pp. 16-24 (2013).

13. Mousavi, S.M., Tavakkoli-Moghaddam, R., Azaron, A., Mojtahedi, S., and Hashemi, H. "Risk assessment for highway projects using jackknife technique", $E x$ pert Systems with Applications, 38(5), pp. 5514-5524 (2011).

14. Hashemi, H., Mousavi, S.M., and Mojtahedi, S.M.H. "Bootstrap technique for risk analysis with interval numbers in bridge construction projects", Journal of Construction Engineering and Management, 137(8), pp. 600-608 (2011).

15. Vahdani, B., Mousavi, S.M., Hashemi, H., Mousakhani, M., and Tavakkoli-Moghaddam, R. "A new compromise solution method for fuzzy group decision-making problems with an application to the contractor selection", Engineering Applications of Artificial Intelligence, 26(2), pp. 779-788 (2013).

16. Schinas, O. "Examining the use and application of multi-criteria decision making techniques in safety assessment", in International Symposium on Maritime Safety, Security and Environmental Protection (2007).

17. Fazil, A., Rajic, A., Sanchez, J., and McEwen, S. "Choices, choices: the application of multi-criteria decision analysis to a food safety decision-making problem", Journal of Food Protection, 71(11), pp. 2323-2333 (2008).

18. Jozi, A.S. and Pouriyeh, A.A. "Health-safety and environmental risk assessment of power plants using multi criteria decision making method", Chemical Industry and Chemical Engineering Quarterly, 17(4), pp. 437449 (2011).

19. Mangalathu, S.G., Shanmugam, N.S., Sankaranarayanasamy, K., Ramesh, T., and Muthukumar, K. "System safety in LPG fired furnace - A multi criteria decision making technique", Advances in Production Engineering \& Management, 7(2), pp. 123-134 (2012).
20. Zadeh, L.A. "Fuzzy sets", Information and Control, 8(3), pp. 338-353 (1965).

21. Kahraman, C., Onar, S.C., and Oztaysi, B. "Fuzzy multicriteria decision-making: a literature review", International Journal of Computational Intelligence Systems, 8(4), pp. 637-666 (2015).

22. Bao, Q. "Multi-criteria decision making techniques for combining different sets of road safety performance indicators into an overall index", Master's Thesis of Transportation Science at Hasselt University (2010).

23. Mojtahedi, S.M.H., Mousavi, S.M., and Makui, A. "Project risk identification and assessment simultaneously using multi-attribute group decision making technique", Safety Science, 48(4), pp. 499-507 (2010).

24. Mousavi, S.M., Tavakkoli-Moghaddam, R., Hashemi, H., and Mojtahedi, S.M.H. "A novel approach based on non-parametric resampling with interval analysis for large engineering project risks", Safety Science, 49(10), pp. 1340-1348 (2011).

25. Khorasani, G., Mirmohammadi, F., Hassan Motamed, M.F., Tatari, A., Verki, M.R.M., Khorasani, M., and Fazelpour, S. "Application of multi criteria decision making tools in road safety performance indicators and determine appropriate method with average concept", International Journal of Innovative Technology and Exploring Engineering (IJITEE), 3(5) (2013).

26. Skorupski, J. "Multi-criteria group decision making under uncertainty with application to air traffic safety", Expert Systems with Applications, 41(16), pp. 7406-7414 (2014).

27. Torra, V. and Narukawa, Y. "On hesitant fuzzy sets and decision", in Fuzzy Systems, FUZZ-IEEE 2009, IEEE International Conference on (2009).

28. Torra, V. "Hesitant fuzzy sets", International Journal of Intelligent Systems, 25(6), pp. 529-539 (2010).

29. Farhadinia, B. "A novel method of ranking hesitant fuzzy values for multiple attribute decision-making problems", International Journal of Intelligent Systems, 28(8), pp. 752-767 (2013).

30. Yu, D., Zhang, W., and Xu, Y. "Group decision making under hesitant fuzzy environment with application to personnel evaluation", Knowledge-Based Systems, 52, pp. 1-10 (2013).

31. Wang, J.Q., Wang, D.D., Yu Zhang, H., and Chen, X.H. "Multi-criteria outranking approach with hesitant fuzzy sets", OR Spectrum, 36(4), pp. 1001-1019 (2014).

32. Zhang, Y., Wang, Y., and Wang, J. "Objective attributes weights determining based on Shannon information entropy in hesitant fuzzy multiple attribute decision making", Mathematical Problems in Engineering, 2014, pp. 30-36 (2014).

33. Rodríguez, R.M., Martínez, L., Torra, V., Xu, Z., and Herrera, F. "Hesitant fuzzy sets: state of the art and future directions", International Journal of Intelligent Systems, 29(6), pp. 495-524 (2014). 
34. Pei, Z. and Yi, L. "A note on operations of hesitant fuzzy sets", International Journal of Computational Intelligence Systems, 8(2), pp. 226-239 (2015).

35. Yan, X. "An approach to evaluating the risk of marketing with hesitant fuzzy information", IJACT: International Journal of Advancements in Computing Technology, 4(9), pp. 122-128 (2012).

36. Yu, D., Wu, Y., and Zhou, W. "Generalized hesitant fuzzy Bonferroni mean and its application in multicriteria group decision making", Journal of Information and Computational Science, 9(2), pp. 267-274 (2012).

37. Xu, Z. and Zhang, X. "Hesitant fuzzy multi-attribute decision making based on TOPSIS with incomplete weight information", Knowledge-Based Systems, 52, pp. 53-64 (2013).

38. Liu, H. and Rodríguez, R.M. "A fuzzy envelope for hesitant fuzzy linguistic term set and its application to multicriteria decision making", Information Sciences, 258, pp. 220-238 (2014).

39. Liu, D.-N. "Model for evaluating the electrical power system safety with hesitant fuzzy linguistic information", Journal of Intelligent \& Fuzzy Systems, 29(2), pp. 725-730 (2015).

40. Chen, N., Xu, Z., and Xia, M. "Interval-valued hesitant preference relations and their applications to group decision making", Knowledge-Based Systems, 37, pp. 528-540 (2013).

41. Farhadinia, B. "Information measures for hesitant fuzzy sets and interval-valued hesitant fuzzy sets", Information Sciences, 240, pp. 129-144 (2013).

42. Li, L.-G. and Peng, D.-H. "Interval-valued hesitant fuzzy Hamacher synergetic weighted aggregation operators and their application to shale gas areas selection", Mathematical Problems in Engineering, 2014, pp. 1-25 (2014).

43. Zhang, X. and Xu, Z. "Interval programming method for hesitant fuzzy multi-attribute group decision making with incomplete preference over alternatives", Computers \& Industrial Engineering, 75, pp. 217-229 (2014).

44. Torra, V. and Narukawa, Y., Modeling Decisions: Aggregation Operators and Information Fusion, Springer (2007).

45. Fan, Z.-P., Ma, J., and Zhang, Q. "An approach to multiple attribute decision making based on fuzzy preference information on alternatives", Fuzzy Sets and Systems, 131(1), pp. 101-106 (2002).

46. Wang, Y.-M. and Parkan, C. "A general multiple attribute decision-making approach for integrating subjective preferences and objective information", Fuzzy Sets and Systems, 157(10), pp. 1333-1345 (2006).

47. Chen, C.-F. and Lee, C.-L. "Determining the attribute weights of professional conference organizer selection: an application of the fuzzy AHP approach", Tourism Economics, 17(5), pp. 1129-1139 (2011).
48. Feng, X., Zuo, W., Wang, J., and Feng, L. "TOPSIS method for hesitant fuzzy multiple attribute decision making", Journal of Intelligent and Fuzzy Systems, 26(5), pp. 2263-2269 (2014).

49. Atanassov, K.T. "Intuitionistic fuzzy sets", Fuzzy Sets and Systems, 20(1), pp. 87-96 (1986).

50. Atanassov, K.T. "More on intuitionistic fuzzy sets", Fuzzy Sets and Systems, 33(1), pp. 37-45 (1989).

51. Atanassov, K.T. "Two theorems for intuitionistic fuzzy sets", Fuzzy Sets and Systems, 110(2), pp. 267-269 (2000).

52. Xia, M. and $\mathrm{Xu}, \mathrm{Z}$. "Hesitant fuzzy information aggregation in decision making", International Journal of Approximate Reasoning, 52(3), pp. 395-407 (2011).

53. Liao, H., Xu, Z., and Xia, M. "Multiplicative consistency of hesitant fuzzy preference relation and its application in group decision making", International Journal of Information Technology \& Decision Making, 13(1), pp. 47-76 (2014).

54. Gitinavard, H., Mousavi, S.M., and Vahdani, B. "Soft computing-based new interval-valued hesitant fuzzy multi-criteria group assessment method with last aggregation to industrial decision problems", Soft Computing, 21(12), pp. 3247-3265 (2017).

55. Wei, G., Zhao, X., and Lin, R. "Some hesitant interval-valued fuzzy aggregation operators and their applications to multiple attribute decision making", Knowledge-Based Systems, 46, pp. 43-53 (2013).

56. Xu, Z. and Xia, M. "Distance and similarity measures for hesitant fuzzy sets", Information Sciences, 181(11), pp. 2128-2138 (2011).

57. Zhu, B., Xu, Z., and Xia, M. "Hesitant fuzzy geometric Bonferroni means", Information Sciences, 205, pp. 7285 (2012).

58. Zhang, Z., Wang, C., Tian, D., and Li, K. "Induced generalized hesitant fuzzy operators and their application to multiple attribute group decision making", Computers \& Industrial Engineering, 67, pp. 116-138 (2014).

59. Zhang, N. and Wei, G. "Extension of VIKOR method for decision making problem based on hesitant fuzzy set", Applied Mathematical Modelling, 37(7), pp. 4938-4947 (2013).

\section{Biographies}

Hossein Gitinavard is currently a $\mathrm{PhD}$ student at the Department of Industrial Engineering and Management Systems, Amirkabir University of Technology, Tehran, Iran. He received his MSc and BSc degrees from the School of Industrial Engineering, Iran University of Science and Technology, and School of Industrial Engineering, University of Tehran, Iran in 2015 and 2013, respectively. His main research interests include fuzzy sets theory, multi-criteria decision-making under uncertainty, supply chain management, and applied 
operations research. He has published several papers in reputable journals and international conference proceedings.

Seyed Meysam Mousavi is an Associate Professor at the Department of Industrial Engineering, Faculty of Engineering, Shahed University in Tehran, Iran. He received a $\mathrm{PhD}$ degree from the School of Industrial Engineering at University of Tehran, Iran, and is currently a member of Iran's National Elite Foundation. $\mathrm{He}$ is the Head of Industrial Engineering Department at Shahed University and a member of the Iranian Operational Research Association. His main research interests include cross-docking systems planning, logistics planning and scheduling, quantitative methods in project management, engineering optimization under uncertainty, multiple-criteria decision making under uncertainty, and applied soft computing. He has published many papers and book chapters in reputable journals and international conference proceedings.
Behnam Vahdani is an Assistant Professor at Faculty of Industrial and Mechanical Engineering, Qazvin Branch, Islamic Azad University in Iran, and is a member of Iran's National Elite Foundation. His current research interests include supply chain network design, facility location and design, multi-criteria decisionmaking, uncertain programming, artificial neural networks, meta-heuristics algorithms, and operations research applications. He has published numerous papers and book chapters in the aforementioned areas.

Ali Siadat is a Professor at Laboratoire de Conception, Fabrication Commande, Arts et Métier Paris Tech, Centre de Metz in Metz, France. His current research interests include computer aided manufacturing, modeling and optimization of manufacturing processes, decision making in manufacturing, inspection planning and operations research applications. He has published numerous papers and book chapters in the aforementioned fields. 